\title{
Online consumer response: key variables affecting consumers' value perceptions
}

\author{
O. Discombe \\ Luton Business School, University of Luton, UK
}

\begin{abstract}
This paper attempts to provide a better understanding of the relationship between consumer perceptions of a brand and their web site, and the perceived value of that web site. This is done by empirically testing the relationship between four key consumer perception variables, i.e. brand personality, involvement, perceived control and expectations, and the perceived value of the web site in an experimental study of consumers' interaction with car brand web sites. Laboratory based, controlled and randomised experiments using three equal sized samples under three experimental conditions were designed. Seventy-eight participants were randomly allocated to three different web site interactions as the experimental treatments. The multiple regression models showed that the four independent variables taken together, rather than in isolation, predict the dependent variable, and account for $70 \%$ of the variation in perceived value. This finding supports the argument that these four consumer-based perceptions measured after the web site interaction can successfully predict the overall value of the web site as perceived by those consumers. Theoretical and managerial implications of this finding are further discussed.

Keywords: online consumer response, brand web sites, added value, perceived value, brand personality, involvement, perceived control, expectations.
\end{abstract}

\section{Introduction}

Since the early days of the commercial use of the Internet, there has been great interest, both from academics and practitioners, into understanding how the online medium would affect consumer behaviour and response to brands. Most of the academic literature tends to be conceptual in nature, generally suggesting 
that consumers have more choice and control over their interactions with companies. The limited amounts of empirical research into consumer behaviour on the Internet generally concentrate on online shopping motives and intentions. There is a bias towards online retailing, with very little research done on consumer perceptions and attitudes to non-shopping web sites. A recent review on consumer behaviour online [1] concluded that research in this area is fragmented; and that there is a clear need for developing and empirically testing conceptual models in consumer behaviour online. Hence, the aim of this paper is to present our quantitative findings about the key variables, i.e. brand personality, involvement, perceived control and expectations, affecting consumers' perceptions of web site value within the context of a non-shopping web site interaction.

\section{The concept of value in the literature}

The term 'value' has been widely used in marketing and branding literature as a tool to create sustainable competitive advantage and long-term customer relationships $[2,3]$. Yet, the exact definition of added value varies considerably, from adding financial value to the company or brand [4] to adding tangible or intangible benefits to maximise perceived value by customers [5].

Branding literature in general looks at the concept of added value from the customers' point of view, and defines added values as additional benefits, which differentiate the brand from competitors and justify the price premium $[6,7,8]$.

Within the Internet context, there is limited literature about adding value to brands. Although McWilliam et al. [9] do not directly use the term 'added value', they clearly refer to a similar concept when they argue that commercial web sites have to create distinctive and differential advantage over their traditional competitors in order to be successful. Aldridge et al. [10] similarly talk about 'offering products with unique benefits' as a long-term strategy for businesses on the Internet because they believe that online consumers will be segmented and differentiated by customer benefits.

\section{Key variables affecting consumers' value perceptions}

The value concept relates to the need for brands to provide additional benefits to consumers in their interaction with the brand's web site in order to entice them and encourage them for further visits. The value that consumers get from a web site is likely to be affected by the interactivity of the online medium and the brand's web site, as well as how they perceive the brand attributes, and their own expectations, involvement and empowerment with regard to that web site [11]. Hence, brand personality, involvement, perceived control and expectations are proposed as the key consumer response variables which would have direct effect on how consumers would perceive value from their interactions with brand web sites. These variables are discussed briefly below. 


\subsection{Brand personality}

Brand personality is a widely accepted construct within branding theory, defining the brand 'as a person'; and in many cases, it is a key construct to understand brand associations and choice [12], value and positioning $[6,13]$ and brand identity [8].

Stern [14] discusses the early literature on brand personality and summarises that brands have personality and consumers have mental images of brand personalities. She also argues that the function of brand personality is "to facilitate the transformation of the brand's unique trait bundle into a consumer's mental picture" (p.17).

There is a clear gap in the academic literature regarding the role of brand personality on the Internet, which this study aims to fill. Value is a complex construct intertwined with the definition of a brand as well as the core essence of the brand. It is generally accepted in branding literature that what differentiates a brand from a mere product is the values it offers beyond the physical attributes of the product. The interactivity of the online medium is likely to influence the way consumers perceive brand attributes, such as its personality. This in turn may have an effect on how consumers value that brand's web site and their interaction with it. Hence, it is proposed that consumers who perceive a brand as being exciting on the Internet would also perceive high value from that brand's web site.

\subsection{Involvement}

The Internet differs from mass media in terms of its attributes like direct interaction, the need to 'pull' audiences rather than 'push' messages; and hence, the related challenge to entice and involve users in their interactions with web sites. Brands need to pull active Internet audiences, who have almost endless alternatives, to their own web sites. It has been suggested in the literature that the interactivity of the online medium leads to higher user involvement $[15,16]$. Interaction with a brand web site requires by its nature the active participation of consumers. McWilliam et al. [9] also posited that involvement is higher on the Internet compared to traditional media regardless of the product category. Furthermore, the more involved the users feel with a brand through their interaction with the web site, the more worthwhile and valuable they would consider that interaction. Hence, it is proposed that consumers who are highly involved with a brand web site would also perceive high value from that brand's web site.

\subsection{Perceived control}

The concepts of empowerment of consumers and increased control have also been discussed frequently in the literature, with the resulting consensus that the interactivity of the Internet medium gives consumers more control.

The online medium also gives consumers the opportunity to communicate with the company, and among themselves, by adding direct input to discussions 
or feedback forums. Hence, they will feel empowered in their relationship with that brand. The more empowered they feel, the more value they are likely to perceive from that interaction. Hence, it is proposed that consumers will perceive this empowerment as an added value to the brand. More specifically, consumers who perceive higher levels of control from a web site will also perceive high value from that web site.

\subsection{Expectations}

Consumer expectations are likely to be raised on the Internet due to the perceived ease and efficiency of computer technologies. Consumers expect things to work quicker on the Internet, and they generally expect more from brands. Nilson [17] supports this by stating that the 24-hour availability of services raised customer expectations. Internet also encourages audiences to expect instant gratification from web sites [18]. Hence, in the context of the Internet, it is proposed that in the broadest sense, the rapid technological developments influence customer expectations, as customers generally expect more from brands online as opposed to offline. At the individual brand level, it can be argued that consumers would perceive higher levels of value from web sites where they feel their expectations have been met or exceeded.

In addition to expecting a positive impact of these individual variables on perceived value of a web site, we also posit that all four variables taken together would affect the value perceptions of brand web sites. Hence, it is proposed that:

P1 Consumers who find a brand web site exciting, who feel highly involved with it, who perceive to be in control of their interaction with the web site, and who find the web site as meeting or exceeding their expectations are likely to perceive high value from that web site.

\section{Operationalisation of constructs and selection of measures}

\subsection{Perceived value scale}

An original instrument named "WebQual 4.0" [19] has been used in this study to measure respondents' perceived value of the web sites. This 22 -item scale, based on the three dimensions of usability, information quality and interaction quality, captures the informational and interactional value, and has the additional dimension of 'usability', which incorporates the navigational and design quality of a web site.

The WebQual instrument fails to incorporate the 'entertainment value' dimension, which is an important quality for any web site. Therefore, Eighmey and McCord's [20] three items were added to the questionnaire to measure the entertainment value of the web site as perceived by consumers.

\subsection{Brand personality}

Aaker's [13] definition and operationalisation of the brand personality construct was adopted for this research, as it is the most valid and widely accepted one 
within marketing and branding literature. Aaker defines brand personality as "the set of human characteristics associated with a brand" (p.347). Her 42-item scale, measuring five dimensions of sincerity, excitement, competence, sophistication and ruggedness, is generally accepted to be a reliable, valid and generalisable measure in branding literature. The 'Excitement' dimension of Aaker's brand personality scale is particularly relevant to the Internet context, as it comprises of the following traits: daring, trendy, exciting, spirited, cool, young, imaginative, unique, up-to-date, independent and contemporary. Most of these traits are inherently present in the Internet context.

\subsection{Involvement}

Zaichkowsky's [21] 10-item Revised Personal Involvement Inventory was used to measure the respondents' involvement with the brand web sites. Zaichkowsky defined involvement as a person's perceived relevance of the object based on inherent needs, values and interests. As this definition recognises past definitions of involvement, and is a context-free measure applicable to involvement with products, advertisements and purchase situations, it was the most suitable scale to use in this study.

\subsection{Perceived control}

A 4-item semantic differential scale was used to measure the respondents' perception of control over their interactions with brand web sites. This scale is based on Mehrabian and Russell's [22] dominance dimension of the PleasureArousal-Dominance (PAD) scale, and was revised by Havlena and Holbrook [23] in 1986.

\subsection{Expectations}

To measure the expectations construct, respondents were asked to rate the brand web site with respect to their expectations on a 5-point Likert scale (much worse than / worse than / about as / better than / much better than expected) as recommended by Danaher and Haddrell [24].

\section{Research design and methodology}

To test the joint effects of the excitement dimension of brand personality, involvement, perceived control and expectations on perceived value, experiments were designed using three car brand web sites as stimuli. The UK automotive industry was chosen as the setting for this study as it provides a relevant context for this research. Due to the global nature of the automotive industry, most car brands are familiar to consumers. All car brands have an Internet existence, varying from just corporate and brand information to online sales and customer service. As the market leader brands are likely to have similar brand recognition due to similar levels of advertising and media exposure, the UK market share values of car brands were used as a proxy to brand familiarity. As Ford, 
Vauxhall and Volkswagen brands were among the top five market leaders at the time of this study, their web sites were used as the experimental stimuli.

It is a common and widely accepted practice to use convenience samples in experimental research, due to resource constraints. Hence, in this study, experimental subjects were recruited from the convenience sample of the Open University staff and students. Invitation e-mails were sent out to about a total of 1000 staff and students asking for their participation in this research. As a result, 78 volunteers were recruited, which gives about a $7.8 \%$ response rate. This relatively low response rate is understandable as the volunteers were asked to give over an hour of their time in a specified computer laboratory for no financial return. It was purposefully decided not to monetarily compensate for volunteers' time in order to emulate a more realistic web site browsing activity where consumers interact with brand web sites entirely in a voluntary fashion, investing their time and money usually in the form of Internet connection charges.

The required sample size for this study was calculated a priori to be somewhere between 22 to 53 subjects per treatment group, assuming an effect size of medium to large, and a power of 0.80 at a $5 \%$ significance level $(\alpha=0.05)$. Hence, the 78 volunteers randomly allocated to three groups resulting in a sample size of 26per group were satisfactory.

All aspects of manipulation were held constant by the use of standard questionnaires, equipment, instructions and environment. Experiments took place in several sessions in specially designated computer labs using the previously set up personal computers with Internet connection to browse prespecified brand web sites. The overall session for the experiments lasted about an hour.

\section{Empirical findings}

The sample consisted of 55 staff and 23 post-graduate students, of which 26 were males and 52 were females. Eighty-three percent of subjects were between 25 and 54 years of age, with the remainder of subjects being under $25(12 \%)$ or over $55(5 \%)$. These distributions are not too different from national statistics, where $65 \%$ of all adults who accessed the Internet were between 25 and 54 years of age, $18 \%$ were under 25 , and $17 \%$ were over 55 years [25]. Over $60 \%$ of subjects were educated to postgraduate level, which was an expected bias due to the nature of participants in the research.

The internal consistency of each scale used in the questionnaires was explored through calculating Cronbach's alpha values for each scale and item-tototal correlations for each item in the scales. All item-to-total correlations surpassed .30, which has been suggested as an appropriate item-to-total criterion [26]. The reliability coefficients for all scales were significantly higher than the recommended lower limit of .70 [27, 28]. Hence, it can be stated with confidence that the scales used in this study are highly consistent and reliable.

The proposition introduced in section 3 was restated as a testable hypothesis as follows: 
H1 The joint effects of brand personality, involvement, perceived control and expectations on perceived value.

$\mathrm{H}_{0}$ : There will be a zero or negative correlation between the combined effects of brand personality, involvement, perceived control and expectations, and the perceived value mean scores.

$\mathrm{H}_{1}$ : There will be a significant positive correlation between the combined effects of brand personality, involvement, perceived control and expectations, and the perceived value mean scores.

This hypothesis requires a multivariate analysis to determine the joint effects of brand personality, involvement, perceived control and expectations on perceived value of the web site. Multiple regression analysis was utilised to this effect.

The results showed that the association between the dependent and independent variables was very strong (Multiple $\mathrm{R}=0.85$ ). Together, excitement dimension of brand personality, involvement with the brand, perceived control of the web site and expectations from the web site accounted for $70 \%$ of the variation in perceived value (adjusted $\mathrm{R}^{2}$ ). All independent variables positively related to perceived value. The regression coefficients and confidence intervals are summarised in Table 1.

Table 1: $\quad$ Regression coefficients and confidence intervals.

\begin{tabular}{|l|c|c|}
\hline Independent variable & $\begin{array}{l}\text { Unstandardised regression } \\
\text { coefficients }\end{array}$ & 95\% Confidence Intervals \\
\hline Brand personality & 0.73 & $0.374-1.077$ \\
\hline Involvement & 0.43 & $0.006-0.85$ \\
\hline Perceived Control & 0.95 & $0.253-1.641$ \\
\hline Expectations & 8.989 & $4.442-13.529$ \\
\hline
\end{tabular}

Since the confidence limits did not encompass a negative value, it can be concluded that the population regression coefficients for all independent variables are positive (Excitement dimension of brand personality: $t=4.119$, $\mathrm{p}<0.001$; Involvement: $\mathrm{t}=2.021, \mathrm{p}=0.047$; Perceived Control: $\mathrm{t}=2.72$, $\mathrm{p}=0.008$; Expectations: $\mathrm{t}=3.942, \mathrm{p}<0.001)$. All the probability values are less than $5 \%$, which suggest that the regression coefficients for all variables are unlikely to have arisen by sampling error. Analysis of variance showed that the regression model, with the four independent variables, was statistically significant $(\mathrm{F}=46.108, \mathrm{df}=4, \mathrm{p}<0.001)$. Hence, the null hypothesis is rejected.

The standardised regression coefficients show that the excitement dimension of brand personality $(0.378)$, and expectations $(0.316)$ are stronger predictors than involvement (0.18) and perceived control (0.187). All variables are, however, positively and significantly related to perceived value.

Individual regression analyses run between perceived value and each of the four independent variables looked at these relationships in isolation; and gave a regression equation to predict values of the dependent variable from each of the 
independent variable in question. These equations are summarised in Table 2 below.

Table 2: $\quad$ Separate regression equations for each independent variable.

\begin{tabular}{|l|l|c|}
\hline Independent variable & Dependent variable & Adjusted $\mathbf{R}^{2}$ \\
\hline $\begin{array}{l}\text { Excitement dimension of } \\
\text { brand personality }\end{array}$ & Perceived Value of the web site & 0.56 \\
\hline Involvement & Perceived Value of the web site & 0.45 \\
\hline Perceived control & Perceived Value of the web site & 0.24 \\
\hline Expectations & Perceived Value of the web site & 0.48 \\
\hline
\end{tabular}

The adjusted $\mathrm{R}^{2} \mathrm{~s}$ showed that the variance explained by each independent variable ranged from 0.24 to 0.56 . Multiple regression model showed that the four independent variables taken together, rather than in isolation, predict the dependent variable better; and account for a higher level of variance explained (Multiple Adjusted $\mathrm{R}^{2}=0.70$ ); and hence represent a better model fit.

\section{Conclusions and managerial implications}

The concept of creating value to both brands and consumers via the web site has been conceptually discussed in the literature. However, empirical studies into the value of web sites or on consumer-based perceptions are rare. Hence, this paper adds to the limited amount of literature by providing empirical evidence regarding the positive effect of key consumer response variables on consumers' perceived values from web sites.

This paper contributes to marketing theory by providing a strong validation for the conceptual model, where the excitement dimension of brand personality, involvement, perceived control and expectations were formulated as the antecedents to the perceived value of a web site. In other words, these four consumer-based perceptions measured after the web site interaction can successfully predict the overall value of the web site as perceived by those consumers. This finding is very important managerially, as it suggests that brand owners can create better value for their online customers or users by making their brand personality more exciting online, by involving customers with the brand and the web site, by giving them more control over their interaction with the web site, and finally, by meeting or exceeding customer expectations online.

\section{References}

[1] Monsuwe, T., Dellaert, B.G.C. \& de Ruyter, K. What drives consumers to shop online? A literature review. International Journal of Service Industry Management, 15 (1), pp. 102-121, 2004.

[2] Macrae, C. World Class Brands. Addison Wesley: Wokingham, 1991. 
[3] Pearson, S. Building Brands Directly - Creating Business Value from Customer Relationships. MacMillan Press Ltd: London, 1996.

[4] Doyle, D.P. Adding Value to Marketing. Kogan Page: London, 1998.

[5] Nilson, T.H. Value-Added Marketing. Marketing management for superior results. McGraw-Hill: London, 1992.

[6] de Chernatony, L. \& McDonald, M. Creating Powerful Brands in Consumer, Service and Industrial Markets. 2nd ed. ButterworthHeinemann: Oxford, 1998.

[7] Jones, J.P. What's in a name? Advertising and the Concept of Brands. Lexington Books: New York, 1986.

[8] Kapferer, J. Strategic Brand Management. $2^{\text {nd }}$ ed. Kogan Page: London, 1992.

[9] McWilliam, G., Hammond, K. \& Diaz, A. Going places in Webtown: A new way of thinking about advertising and the Web. The Journal of Brand Management, 4 (4), pp. 261-270, 1997.

[10] Aldridge, A., Forcht, K. \& Pierson, J. Get linked or get lost: marketing strategy for the Internet. Internet Research, 7 (3), pp.161-169, 1997.

[11] Discombe, O. The effect of interactivity on online consumer response: an investigation into the UK car brand websites. $\mathrm{PhD}$ Thesis. The Open University, School of Management, Milton Keynes, 2004.

[12] Aaker, D.A. Managing Brand Equity: Capitalizing on the Value of a Brand Name. The Free Press: New York, 1991.

[13] Aaker, J.L. Dimensions of Brand Personality. Journal of Marketing Research, 34 (August), pp. 347-356, 1997.

[14] Stern, B.B. The Firm, the Author, and the Persona: A Literary Model of the Source of Advertising. Journal of Current Issues \& Research in Advertising, 15 (2), pp. 15-24, 1993.

[15] Evans, J.R. \& King, V.E. Business-to-Business Marketing and the World Wide Web: Planning, Managing, and Assessing Web Sites. Industrial Marketing Management, 28, pp. 343-358, 1999.

[16] Liu, Y. \& Shrum, L.J. What Is Interactivity and Is It Always Such a Good Thing? Implications of Definition, Person, and Situation for the Influence of Interactivity on Advertising Effectiveness. Journal of Advertising, 31 (4), pp. 53-64, 2002.

[17] Nilson, T.H. Competitive Branding. Winning in the market place with value-added brands. John Wiley \& Sons Ltd: Chichester, 1998.

[18] ClickZ Network. www.searchz.com/clickz/071598.shtml

[19] Barnes, S.J. \& Vidgen, R.T. An Integrative Approach to the Assessment of E-Commerce Quality [online working paper], University of Bath. www.webqual.co.uk/papers/webqualbookshop.pdf.

[20] Eighmey, J. \& McCord, L. Adding Value in the Information Age: Uses and Gratifications of Sites on the World Wide Web. Journal of Business Research, 41, pp. 187-194, 1998.

[21] Zaichkowsky, J.L. The Personal Involvement Inventory: Reduction, Revision, and Application to Advertising. Journal of Advertising, 23 (4), pp. 59-70, 1994. 
[22] Mehrabian, A. \& Russell, J. An Approach to Environmental Psychology. The MIT Press: Cambridge, MA, 1974.

[23] Havlena, W.J. \& Holbrook, M.B. The Varieties of Consumption Experience: Comparing Two Typologies of Emotion in Consumer Behavior. Journal of Consumer Research, 13 (December), pp. 394-404, 1986.

[24] Danaher, P.J. \& Haddrell, V. A comparison of question scales used for measuring customer satisfaction. International Journal of Service Industry Management, 7 (4), pp. 4-26, 1996.

[25] Office for National Statistics National Statistics Omnibus Survey. London, 2002.

[26] Henryson, S. Gathering, analyzing, and using data on test items. Educational Measurement, ed. R. L. Thorndike, American Council on Education: Washington, D.C, pp. 153, 1971.

[27] Nunnally, J.C. Psychometric Theory. 2nd ed. McGraw-Hill: New York, 1978.

[28] Pedhazur, E.J. \& Schmelkin, L.P. Measurement, Design, and Analysis. An Integrated Approach. Lawrence Erlbaum Associates: Hillsdale, NJ, 1991. 